\title{
Investigating Association Between Participation in Co-curricular Activities and Student's Academic Output at Secondary Level
}

\section{Yusra Sarwat}

Educational Planning, Policy Studies, and Leadership (EPPSL) Department, Allama Iqbal Open University, Islamabad, Pakistan

\section{Hamid Ali Nadeem}

Educational Planning, Policy Studies, and Leadership (EPPSL) Department, Allama Iqbal Open University, Islamabad, Pakistan https://orcid.org/0000-0002-9031-6513

Namood-e Sahar ( $\square$ namoodmphil17@nip.edu.pk)

National Institute of Psychology, Quaid-i-Azam University, Islamabad, Pakistan. https://orcid.org/00000003-2086-4482

\section{Research Article}

Keywords: co-curricular activities, students, learning outcomes, growth and development, educational experiences

Posted Date: August 5th, 2020

DOI: https://doi.org/10.21203/rs.3.rs-51589/v1

License: (9) This work is licensed under a Creative Commons Attribution 4.0 International License. Read Full License 


\section{Abstract}

Educational experiences are necessary for ensuring student's growth, skill development, and a successful life. The educational experiences are governed by the student's learning outcomes. Co-curricular activities also form a significant part of student's life and are found to play a vital role in the academic as well as personal growth and development of children. The present research studied the role of co-curricular activities in student's learning outcomes at secondary level. The results support association between both variables as assessed by Murphy's student survey questionnaire. Findings could help to provide evidence for importance of curricular activities to the policy makers so it can be made a part of student's learning outcomes.

\section{Introduction}

\section{Learning and Learning Outcomes}

Learning is the acquiring of new or the modification of already existing knowledge, skill, and information. It is a continuous process that occurs at both conscious and unconscious level. Learning, although, is a part of everyone's life forms a strong connection with students. The learning among the students is guided through the set of learning outcomes. Student learning outcomes are the measures which explain extent to which a student or group of students may have knowledge upon an academic program or degree completion (Gross, 2010, p. 158). They are of great significance as are responsible for establishment of learning goals for the learners (Barrett, 2011; Lawlor, 2012), assist teachers to direct the learning process (Bobish, 2011; Hirsto et al., 2013; Watson, 2002), provide way to develop the assessment (Anderson et al., 2005; Keshavarz, 2011). For the present study student's learning outcomes are based on the learning outcomes by Chicago Metropolitan Area Community College (CMACC), which comprised of reading, writing, scientific literacy, critical thinking, technology literacy, information literacy, and global awareness.

Reading. It is defined by CMACC as the ability of students to read, drawing conclusions, understanding text, extracting the main ideas and responding critically to texts from a variety of subjects. With the learning outcome of reading, the associated objective is reading effectively.

Writing. It has been identified by CMACC as the students' ability to (a) write clear, mechanically correct, and well-ordered essay; (b) exhibits an understanding of the rationale, and of addressees; and (c) utilizes required quantitative tools, certification and credentials when necessary (CMACC, 2009). The learning objectives related to the learning outcome of writing are writing clearly, utilizing documentation to support writing and demonstrating audience and purpose in writing.

Scientific literacy. It has been identified by CMACC (2009) as the student's ability to (a) scrutinize the interrelationships from scientific data and understand the information (b) make appropriate predictions to draw valid conclusions (c) exhibit the capacity of generalize information from specified information. 
Learning objectives associated with this outcome are, understanding scientific information, generalizing scientific information, and making appropriate predictions from scientific information.

Quantitative literacy. It has been identified as the student's ability to (a) ability to perform symbolic manipulation, solve system of equations (b) represent existent problems of the world by identifying accurate data, defining variables (CMACC, 2009). The objectives related with this outcome are; carrying out symbolic manipulation, representing real world problems and analyzing and interpreting information

Critical thinking. It has been identified by CMACC (2009) as the student's capacity to (a) examine, analyze and understand information and meaning of the context, categorize by information by clarifying meaning in context, categorizing, recognize and analyze arguments into their component elements, (b) analyze ideas by assessing arguments and justifying procedures, (c) make predictions, select alternatives and draw conclusions, (d) exhibit inductive reasoning skills and; (e) exhibit deductive reasoning skills (CMACC, 2009). The objectives related with outcome are analyzing and interpreting information, evaluating ideas, making predictions, and exhibiting deductive and inductive reasoning skills

Technology literacy. CMACC has defined the learning outcome of technology literacy as the student's ability to use electrical technology for learning (CMACC, 2009). The associated learning outcome is using electrical technology for learning.

Information literacy. The student's ability to identify information needs to locate, use and evaluate information effectively and appropriately is defined as the $7^{\text {th }}$ learning outcome i.e. information literacy by CMACC (2009). Objective related with this outcome is; identifying information needs to locate, evaluate and use information effectively.

Global awareness. The learning outcome of global awareness has been defined as the student's expression of increased awareness of global issues and different cultures (CMACC, 2009). This outcome has two related objectives which are increased understanding of global issues and increased understanding of different cultures.

\section{Co-curricular Activities}

The International Dictionary of Education (Page et al., 1977) has defined co-curricular activities as activities sponsored or recognized by a school or college which are not part of the academic curriculum but are acknowledged to be an essential part of the life of an educational institution. Co-curricular activities include sports, school bands, student newspaper etc. They may also be classed as extracurriculari.e. activities carried on outside the regular course of study; activities outside the usual duties of a job, as extra class activities.

The school curriculum is not solely responsible for the child development and learning. For the overall development of the child personality in academic and non-academic fields; classroom teaching should be supplemented with co-curricular activities. Such activities help to develop various facets of the 
personality of the child and students as they have wide horizon to cater to the cultural, social, emotional, physical, spiritual moral and aesthetic development of the child. To polish the intellectual aspects of students and for their artistic, aesthetic, character, spiritual, moral, and physical development cocurricular activities bear great significance. Along with these bigger aspects of personality building cocurricular activities also favour management, organization, regulation, speech smoothness, informal expressions and self-belief construction among the students etc. Co-curricular activities help students to speculate into various professional fields like music, fashion, art, painting, printing, photography and many others. That's why co-curricular activities are necessary to enhance skill development in the students. The main types of the co-curricular activities are stated below

Literary activities. Literary activities include card making, making projects like dying, cutting, printing designs on wood etc.

Physical development activities. Such activities include sports like running, frog jump, cricket, basketball. In schools and colleges sports weeks are conducted to highlight their importance. These are the activities of interest of almost every student.

Aesthetic and cultural development activities. Such activities include dramas and stage shows organized on cultural and traditional themes. In many schools, cultural weeks are organized to show attachment to traditions and cultures. These activities are important for delivering lesson, changing minds and for moral development of students.

Civic development activities. These activities include debates, speeches, writing articles, essays, story writing, storytelling etc.

Social welfare activities. Social welfare activities include making welfare camps, scouts, making council rooms, first aid houses, donation collection and delivery etc.

Leisure time activities. These activities depend on the choice and interest of students. They may include drawing, singing, dancing, cooking, weaving, sewing etc.

Excursion activities. For excursion activities less, number of students get permission from their parents to participate as they include camping, tour, trips, hiking etc.

\section{Rationale of Study}

Now a day's students pay more attention to indoor activities, video and mobile games and do not participate in physical or literary activities (Fang et al., 2017). But outdoor and co-curricular activities are the demand for their proper growth and development in social and academic areas (Bento and Dias, 2017; Huang and Chang, 2004), therefore their importance should be highlighted, and they should be stressed upon by the schools. The objective could be achieved through research for seeking evidence on association between co-curricular activities and student academic outcomes. The findings of this study will be useful to know how far the extra-curricular activities are important to the students, awareness on 
the advantage of being active in co-curriculum. Participation in extra-curricular activities is one such strategy, as it allows students to demonstrate competencies not otherwise visible in their resumes due to limited job experience. Literature has revealed that participation in co-curricular activities benefits students' retention rates and educational outcomes (Leung et al., 2011; Lourens, 2014).

The present study evaluates these perceptions of student's involvement in co-curricular activities in order to establish a baseline for future studies. Moreover, this study will contribute ideas for the development of co-curricular activities in respect to things that influence student's learning. Result of this study can be used as a conceptual contribution in the context of refinement of the concept and implementation of educational practice as a strategic effort in developing human resources. Other than that, the results of this study are expected to benefit the students, teachers and parents as well as an evaluation of material inputs in improving the co-curricular activities can be acquired from it that can positively affect the students learning activities in the classroom.

\section{Methods}

\section{Sample}

The sample of the study was approached at different public and private sector schools. It comprised of 100 school students who were engaged in different co-curricular activities; such that, 68 were female and 32 were male.

\section{Research Instrument}

A structured questionnaire i.e. student survey instrument developed by Murphy (2002) was used as research instrument. It has 18 items and 8 subscales namely; reading, writing, scientific literacy, quantitative literacy, critical thinking, technology literacy, information literacy, and global awareness. It is a 5-point Likert type scale on which respondents are to indicate their level of agreement or disagreement with a given statement; such that, 1 denotes strong agreement and 5 denotes strong disagreement. The reliability for the scale is .69 , indicating consistency of scores.

\section{Procedure}

The sample of students who take part in co-curricular activities was approached at different public and private schools. The instrument was to be filled by the teachers about the learning outcome of the students along with their respective age and gender. The administration was carried out after the permission from school authorities acquired by guiding them about the objectives and significance of study. The teachers were thanked after the administration for their time and responses.

\section{Results}


The data collected was used to determine the psychometric characteristics of the instrument including mean, standard deviation, and coefficient of reliability. The values (cited as Table 1) demonstrate that the scores exhibit low variance and thus the data has low spread. Reliability coefficients indicate that total and all the subscales possess significant reliabilities ranging from .4 to .7 (Anastasia, 2003). This show that all the items results in consistent scores.

The correlation among gender and the student's learning outcome $s$ was also estimated. The results (cited as Table 2) indicate that female students when actively participate in co-curricular activities they score more in the learning outcome of information literacy. Similarly, when boys actively participate in cocurricular activities, they score high in the learning outcomes of scientific literacy and technical literacy. Participation in co-curricular activities shows significant positive relations with the learning outcomes of reading, writing, critical thinking, technical literacy, information literacy at .05 level of significance (i.e., $95 \% \mathrm{Cl}$ ) and with global awareness at .01 level of significance (i.e., $99 \% \mathrm{Cl}$ ). But the analysis reveals that participation in co-curricular activities does not show significant results with learning outcome of reading and quantitative literacy. These findings demonstrate that there exists a positive relation between cocurricular activities and student learning outcomes.

\section{Discussion And Conclusion}

The study found a significant positive correlation between student learning outcomes (i.e., writing, scientific literacy, technology literacy, information literacy and global awareness) and participation of students in co-curricular activities. Literature also demonstrated that co-curricular activities of students improve the writing ability (Maguire, 2019), scientific, technological, and information literacy (Fisher, 2016; van Griethuijsen et al., 2015), along with the global awareness (Kulturel-Konak et al., 2017; Storey, 2010). Findings also suggest that no significant relation exists for participation in co-curricular activities and learning outcomes of reading and quantitative literacy. No literature evidence was found in support of this finding. It is thus concluded that the participation in co-curricular activities help in the achievement of student learning outcomes.

On the basis of findings from this research study, it is suggested that future researches should be conducted to figure out the extent at which co-curricular activities are useful for the students, and which activities are needed. Moreover, it should be worked upon to find how the learning outcomes of reading and quantitative achievement can be achieved in a much better way. Factors other than co-curricular activities which either positively or negatively impact co-curricular activities should also be studied in future researcher. Gender studies and studies for disabled students in relation to co-curricular activities should also be conducted to fully understand the phenomenon.

\section{Declarations}

The written consent of the participants was properly taken and all ethical considerations were ensured. I, on behalf of all the authors, also state that there exists no conflict of interest. 


\section{References}

Anderson, H. M., Moore, D. L., Anaya, G., \& Bird, E. (2005) Student learning outcomes assessment: a component of program assessment. American Journal of Pharmaceutical Education, 69 (2).

Barrett, A. M. (2011) A Millennium Learning Goal for education post-2015: a question of outcomes or processes. Comparative Education, 47 (1), 119-133.

Bento, G., \& Dias, G. (2017) The importance of outdoor play for young children's healthy development. Porto Biomedical Journal, 2 (5), 157-160.

Bobish, G. (2011) Participation and pedagogy: connecting the social web to ACRL learning outcomes. The Journal of Academic Librarianship, 37 (1), 54-63.

Chicago Metropolitan Area Community College. (2009) 2009-2010 college catalog.

Fang, W. T., Ng, E., \& Chang, M. C. (2017) Physical outdoor activity versus indoor activity: their influence on environmental behaviors. International Journal of Environmental Research and Public Health, 14(7), 797.

Fisher, K. (2016). The Relationship Between Extracurricular STEM Activities and Performance on the Florida Science Assessment (University of Central Florida Orlando. Unpublished PhD. thesis).

Gross, R. (Ed.) (2010) Psychology: The Science of Mind and Behaviour (6th edn) (London, Hodder Arnold Publishers).

Hirsto, L., Lampinen, M., \& Syrjakari, M. (2013) Learning outcomes of university lecturers from a processoriented university pedagogical course. Trames: a Journal of the Humanities and Social Sciences, 17 (4), 347.

Huang, Y. R., \& Chang, S. M. (2004) Academic and cocurricular involvement: their relationship and the best combinations for student growth. Journal of College Student Development, 45 (4), 391-406.

Keshavarz, M. (2011). Measuring course learning outcomes. Journal of Learning Design, 4 (4), 1-9.

Kulturel-Konak, S., Konak, A., \& D'Allegro, M. L. (2017). Global awareness interest of college students. International Journal of Bias, Identity and Diversities in Education (IJBIDE), 2 (1), 13-26.

Lawlor, K. B. (2012) Smart goals: how the application of smart goals can contribute to achievement of student learning outcomes. In Developments in Business Simulation and Experiential Learning: Proceedings of the Annual ABSEL Conference (Vol. 39). San Diego, California.

Leung, C. H., Ng, C. W. R., \& Chan, P. O. E. (2011) Can co-curricular activities enhance the learning effectiveness of students: an application to the sub-degree students in Hong Kong. International Journal of Teaching and Learning in Higher Education, 23 (3), 329-341. 
Lourens, A. (2014) The development of co-curricular interventions to strengthen female engineering students' sense of self-efficacy and to improve the retention of women in traditionally male-dominated disciplines and careers. South African Journal of Industrial Engineering, 25 (3), 112-125.

Maguire, A. (2019) Extracurriculars to Consider if You Intend to Study Writing. Available at: https://blog.collegevine.com/extracurriculars-writing/

Murphy, R. K. (2002) Contributions to the Attainment of Learning Outcomes Through Co-Curricular Activities: Perceptions from Students at Bowling Green State University (Bowling Green State University. Unpublished PhD. thesis).

Page, G. T., Thomas, J. B., \& Marshall, A. R. (Eds.) (1977) International dictionary of education (California, Kogan Page)

Storey, K. L. (2010). Bridging the Gap: Linking Co-Curricular Activities to Student Learning Outcomes in Community College Students. (National-Louis University. Unpublished PhD. thesis).

van Griethuijsen, R. A., van Eijck, M. W., Haste, H., den Brok, P. J., Skinner, N. C., Mansour, N., ... \& BouJaoude, S. (2015). Global patterns in students' views of science and interest in science. Research in Science Education, 45 (4), 581-603.

Watson, P. (2002) The role and integration of learning outcomes into the educational process. Active Learning in Higher Education, 3 (3), 205-219.

\section{Tables}


Table 1.

Psychometric Characteristics of Student's Survey $(N=100)$

\begin{tabular}{|c|c|c|c|c|}
\hline $\mathrm{Sr} / \mathrm{No}$ & Scale & $M$ & $S D$ & $a$ \\
\hline & Student survey (18 items) & & & .69 \\
\hline Subscale 1 & Reading ( 1 item) & & & .68 \\
\hline 1. & Item 1 & 2.90 & 1.60 & \\
\hline Subscale 2 & Writing (3 items) & & & .73 \\
\hline 2. & Item 2 & 3.46 & 1.59 & \\
\hline 3. & Item 3 & 3.09 & 1.64 & \\
\hline 4. & Item 4 & 3.24 & 1.54 & \\
\hline Subscale 3 & Scientific Literacy ( 3 items) & & & .64 \\
\hline 5. & Item 5 & 4.06 & 1.18 & \\
\hline 6. & Item 6 & 3.16 & 1.57 & \\
\hline 7. & Item 7 & 4.28 & 1.04 & \\
\hline Subscale 4 & Quantitative literacy (2 items) & & & .66 \\
\hline 8. & Item 8 & 3.52 & 1.52 & \\
\hline 9. & Item 9 & 3.02 & 1.64 & \\
\hline Subscale 5 & Critical Thinking (5 items) & & & .71 \\
\hline 10. & Item 10 & 3.43 & 1.39 & \\
\hline 11. & Item 11 & 3.43 & 1.39 & \\
\hline 12. & Item 12 & 4.07 & 1.14 & \\
\hline 13. & Item 13 & 3.43 & 1.39 & \\
\hline 14. & Item 14 & 3.40 & 1.41 & \\
\hline Subscale 6 & Technology Literacy (1 item) & & & .72 \\
\hline 15. & Item 15 & 3.45 & 1.39 & \\
\hline Subscale 7 & Information Literacy (1 item) & & & .70 \\
\hline 16. & Item 16 & 2.46 & 1.42 & \\
\hline Subscale 8 & Global awareness (2 items) & & & .66 \\
\hline 17. & Item 17 & 4.14 & 1.18 & \\
\hline 18. & Item 18 & 4.13 & 1.16 & \\
\hline
\end{tabular}


Table 2.

Correlation Estimates for Gender and Student Learning Outcomes ( $N=100)$

\begin{tabular}{|c|c|c|c|c|c|c|c|c|c|c|}
\hline & Gender & Read & Write & Sen.Lit & Qua_Lit & Cr.lit & Tec_Lit & Inf.Lit & Gl_Aw & P.ccrlr \\
\hline Gender & - & .02 & .08 & $.15^{40}$ & .01 & -.01 & $.14^{94}$ & $-.02^{+4}$ & .03 & $.32^{\prime \prime}$ \\
\hline Read & - & - & -.07 & .03 & .05 & .02 & $-.10^{*}$ & .02 & .02 & -.08 \\
\hline Write & - & - & - & $.78^{* *}$ & $.13^{\circ}$ & $.22^{* *}$ & $.46^{* 4}$ & $-.18^{* 4}$ & $.04^{*}$ & $.38^{* *}$ \\
\hline Sen Lit & - & - & - & - & $.17^{* *}$ & $.28^{* *}$ & $.50^{* *}$ & $-.20^{* *}$ & .06 & $.39^{* *}$ \\
\hline Qua.Lit & - & - & - & - & - & .03 & $.13^{*}$ & $.28^{* *}$ & $.16^{4+}$ & .16 \\
\hline Cr.Thk & - & - & - & - & - & - & $.13^{*}$ & -.10 & .10 & $.18^{* *}$ \\
\hline Tec Lit & - & - & - & - & - & - & - & $-.35^{* *}$ & .03 & $.60^{* *}$ \\
\hline Inf Lit & - & - & - & - & - & - & - & - & -.02 & $.34^{* *}$ \\
\hline Gl.Aw & - & - & - & - & - & - & - & - & - & $.13^{*}$ \\
\hline P.Ccrly & - & - & - & - & - & - & - & - & - & - \\
\hline $\begin{array}{l}\text { Note. Rea } \\
\text { thinking. } \\
\text { p.Ccrlr-pa } \\
{ }_{p<}<.01, " p\end{array}$ & $\begin{array}{l}\text { Tes.Lit } \\
\text { icipatio } \\
.05\end{array}$ & 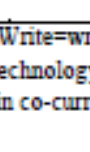 & i & y. & . & tion & $\begin{array}{l}\text { Lif-quant } \\
\text { literacy, }\end{array}$ & $\begin{array}{l}\text { itative li } \\
\text { GLAn }\end{array}$ & $\begin{array}{l}\text { eracy, C } \\
=\text { global }\end{array}$ & $\begin{array}{l}\text { Thk }=c \\
\text { aware }\end{array}$ \\
\hline
\end{tabular}

